\title{
LOS PARATEXTOS A LAS TRADUCCIONES DEL CANCIONERO DE PETRARCA PUBLICADAS EN ESPAÑA (1983-2016) COMO ESPACIO PARA LA REFLEXIÓN ACERCA DE LOS RETOS DE LA TRADUCCIÓN INTERTEMPORAL
}

\author{
Francisco José Rodríguez Mesa \\ Universidad de Córdoba
}

\section{RESUMEN}

Los paratextos se erigen como un espacio privilegiado desde el cual el traductor reflexiona acerca de las principales cualidades del texto que presenta. Teniendo en cuenta este fenómeno, en este estudio se analizan las reflexiones que se vierten en los paratextos de las cuatro traducciones íntegras del Cancionero de Francesco Petrarca publicadas en Espańa entre 1983 y 2016: las dos castellanas de Ángel Crespo y Jacobo Cortines, la gallega de Darío Xohán Cabana y la catalana de Miquel Desclot. En estas obras se indagará en la naturaleza del texto poético traducido para rastrear el grado de apropiación y de paternidad de los traductores sobre el resultado final tomando como base su actuación con respecto a tres factores que remiten a la esfera de la traducción intertemporal: la rima y las dificultades lingüísticas y de contenido presentes en el texto origen.

Palabras Clave: paratextos, traducción poética, Petrarca, Cancionero.

\author{
THE PARATEXTS OF THE TRANSLATIONS OF PETRARCH'S CANZONIERE \\ PUBLISHED IN SPAIN (1983-2016) AS A SPACE FOR REFLECTION \\ ON THE CHALLENGES OF INTERTEMPORAL TRANSLATION
}

\section{Abstract}

Paratexts constitute a privileged space from which the translator reflects on the main qualities of the text he or she is presenting. Taking as a basis this approach, this study analyses the theoretical considerations present in the paratexts of the four complete translations of Petrarch's Canzoniere published in Spain between 1983 and 2016: the two Spanish translations by Ángel Crespo and Jacobo Cortines, the Galician translation by Darío Xohán Cabana and the Catalan one by Miquel Desclot. In these works, the nature of the translated poetic text will be investigated in order to trace the degree of appropriation and paternity of the translators over the final result, based on their actions with regard to three aspects related to intertemporal translation: rhyme and the linguistic and content difficulties present in the source text.

Keywords: paratexts, poetic translation, Petrarch, Canzoniere. 


\section{LA ENCRUCIJADA ENTRE LA TRADUCCIÓN INTERTEMPORAL Y LA POÉTICA: EL CASO DE LOS RERUM VULGARIUM FRAGMENTA $(R V F)$ DE PETRARCA}

Es indiscutible que cualquier traducción conlleva una manipulación, voluntaria o involuntaria, pero este proceso cobra una importancia capital en aquellos casos en los que el texto origen ( $\mathrm{TO}$ ) pertenece a un contexto cultural especialmente remoto, sobre todo, si la distancia a la que aludimos es de naturaleza cronológica. En estos casos, como afirma Cammarota,

La traduzione è simile a un viaggio nel tempo: con la mediazione di un traduttore, il testo di partenza, appartenente a un universo linguistico e culturale del passato, viene messo a contatto con destinatari di un'epoca successiva; i nuovi lettori, dal canto loro, per ragioni diverse si affidano alla guida di un traduttore per risalire i secoli e intraprendere un viaggio esplorativo in un mondo linguisticamente e culturalmente remoto (2018: 10).

Tantas son las especificidades de este viaje en el tiempo que, para el proceso de traducción de textos pertenecientes a épocas remotas, se ha acuñado el término de «traducción intertemporal» (en inglés, «intertemporal translation»o "cross-temporal translation»). Según Shuttleworth y Cowie en su Dictionary of Translation Studies, esta denominación se usa «to refer to the translation of a text by an author writing in (or about) an earlier time [...]. In the case of intertemporal translation across major spans of time there is frequently the problem of the work losing its original contextual significance, or indeed of the genre in which it was written becoming defunct» (1997: 86-87).

En efecto, más allá de la mera distancia temporal, la traducción de textos compuestos en un pasado remoto suele implicar una notable separación cultural entre la audiencia del texto meta (TM) y el contexto de composición y, por ende, de recepción del TO que el traductor debe tratar de solventar ${ }^{1}$. Evidentemente, este cuenta con la inestimable ayuda de una serie de ámbitos del saber que pueden considerarse como auxiliares de esta modalidad de la traducción, desde la ecdótica hasta los estudios literarios.

En cualquier caso, las ya de por sí serias dificultades que conlleva la traducción intertemporal se ven acrecentadas cuando el traductor se embarca en la traslación de un autor cuya obra ha gozado de una cierta repercusión en la cultura meta y estas se ven de nuevo multiplicadas si el TO está sujeto a cualquier tipo de constricción formal, como en el caso de la poesía.

${ }^{1}$ Por expresar la problemática a la que se enfrenta el traductor de este tipo de textos en términos harto conocidos en el ámbito de los estudios de traducción, cabe aludir al principio de la equivalencia dinámica formulado por Nida y Taber y en el marco del cual «Translating consists of reproducing in the receptor language the closest natural equivalent of the source language message, first in terms of meaning, secondly in terms of style» (2003: 12). 
Teniendo en cuenta estos factores teóricos, en este estudio proponemos el análisis de las cuatro traducciones integrales del Cancionero de Petrarca que más repercusión han tenido en España en las últimas décadas y que, en sus diversos ámbitos, siguen utilizándose como textos meta canónicos. Nos referimos a las traducciones al castellano de Ángel Crespo (Bruguera, 1983)² y Jacobo Cortines (Cátedra, 1989)3 , a la gallega de Darío Xohán Cabana (Curuxa, 2012) ${ }^{4}$ y a la catalana de Miquel Desclot (Proa, 2016) 5 . Analizaremos los distintos paratextos que acompañan a estas obras y prestaremos una especial atención a aquellos espacios reservados a la reflexión traductológica donde se solvente el salto, casi ontológico, que separa el TO de la audiencia meta.

En el contexto de recepción en que se sitúan las cuatro obras que conforman el corpus cabe establecer una diferencia significativa, pues, si en castellano las traducciones más o menos íntegras del Cancionero petrarquesco han gozado de una notable fama editorial y traductora ya desde el s. $\mathrm{XvI}^{6}$, la versión de Desclot constituye el primer y único testimonio de la totalidad de la obra del aretino en catalán ${ }^{7}$, mientras

${ }^{2}$ Los estudios acerca de Crespo son numerosos. Para obtener una visión global de su ingente trayectoria como traductor, remitimos al número monográfico que, en su honor, la revista Anthropos publicó en 1989 (vid. AA.VV. 1989); en lo referido a su relación con Italia, es fundamental el estudio de Chieregato (2012). Por lo que respecta a su versión de los Rvf, véanse Aja (2015) y, en perspectiva comparada con Cortines, Mondola (2017). Romera Pastor (2005) también alude a ambas traducciones espańolas.

${ }^{3}$ La traducción de Jacobo Cortines ha sido estudiada por Carrera Díaz (2005) y Mondola (2017), este último poniéndola en relación con la de Crespo. Desde una perspectiva mucho más amplia, también Rodrigo Mora (1996) se ha ocupado de la obra.

${ }^{4}$ El único estudio sobre la traducción gallega de los Rvf es obra de Rodríguez Barcia y Pedreira Rodríguez (2005), si bien este artículo toma como base la primera traducción de las rimas petrarquescas de Cabana, publicada por la Xunta de Galicia en 1989, y no su revisión (véase la nota 8).

${ }_{5}$ Desclot comenzó a traducir composiciones aisladas de los Rvf décadas antes de embarcarse en la tarea de verter la globalidad del Cancionero al catalán y de ello da cuenta Arqués (2005: 142143). No obstante, lo reciente de la publicación de la traducción integral provoca que el único estudio con el que esta cuenta sea una reseña, también obra de Arqués (2017). El mismo Desclot escribió un breve artículo sobre su experiencia traduciendo al aretino (vid. Desclot 2017).

${ }^{6}$ Recuérdense, entre todas ellas, la primera traducción integral, obra de Enrique Garcés, publicada en 1591 y reeditada por la editorial Magisterio Espańol en 1967 al cuidado de Antonio Prieto o, mucho más próxima a los textos de Crespo y Cortines, la versión de Atilio Pentimalli (Ediciones 29, 1976). Para más datos acerca de la fortuna del Cancionero de Petrarca en espańol, se remite a la amplia base de datos del Proyecto Boscán: http://www.ub.edu/boscan.

${ }^{7}$ Es llamativo que la primera versión íntegra de los Rvfno se haya publicado hasta entrado el s. XXI, pues la cultura literaria catalana cuenta con brillantes páginas de influencia petrarquista en su haber, baste consultar el estudio de Espadaler (2015), que ofrece una interesante panorámica de la situación en la lírica medieval. Asimismo, remitimos al profundo estudio de Gavagnin (2010) sobre las traducciones parciales de Petrarca a esta lengua. 
que Cabana es el único traductor de los $R v f$ al gallego, obra de la que publicó una primera traducción en $1989^{8}$.

Asimismo, por lo que respecta a su formato, los cuatro textos analizados distan de ser homogéneos. Por un lado, las versiones de Crespo y Cortines se publicaron originariamente en colecciones de bolsillo, en octavo y con tapa blanda (y este es el formato en el que han continuado reeditándose ${ }^{9}$ ), y, frente a ellas, las obras de Cabana y Desclot han aparecido en cuidados volúmenes de cuarto con tapa dura. Con la única excepción de la traducción de Crespo, las obras muestran el texto original de los $R v f$ a espejo.

Por lo que respecta a la elección del TO, Crespo, Cortines y Desclot dicen haberse basado fundamentalmente en la edición al cuidado de Gianfranco Contini con notas de Daniele Ponchiroli (Petrarca 1964) ${ }^{10}$, mientras que Cabana cita tres títulos como las «edicións que us[ou] pra esta nova tradución» (2012: 30): la de Neri, Martelotti, Bianchi y Sapegno (Petrarca 1951), la cuidada por Chiari (Petrarca 1991) y la de Dotti (Petrarca 1996a).

En lo que atañe al aparato paratextual de cada traducción, si bien algunos de los componentes de cada volumen son comunes a las cuatro obras, cabe destacar ciertas divergencias. Las cuatro traducciones contienen una introducción que sirve de contextualización a la vida, obra e influencia de Petrarca y una sección (separada o no de dicho estudio) en la que cada autor comenta los rasgos que le parecen más sobresalientes de su iter traductor.

Por lo que respecta a las dimensiones, los estudios introductorios de las obras castellanas son marcadamente más amplios que los otros dos. Así, la versión de Crespo va acompañada de un exhaustivo ensayo de 117 páginas que se puede dividir, grosso modo, en tres secciones principales: vida, obra e influencia del aretino (pp. I-cX), observaciones acerca de la traducción (pp. CXI-CXII) y bibliografía (pp. CXIII-CXVII), todo ello obra del mismo traductor. La editorial Cátedra precede la traducción de Cortines con un aparato crítico de 126 páginas, dividido entre unos «Preliminares» del traductor en los que relata con todo detalle el proceso de traslación de los versos petrarquescos (pp. 7-15), un estudio acerca del amante de Laura obra de Nicholas Mann (pp. 19-120) y una bibliografía (pp. 121-126).

${ }^{8}$ Cabe destacar que el texto escogido para este estudio y publicado por Edicións da Curuxa en noviembre de 2012 no es una reedición de la traducción de 1989 (vid. Petrarca 1989b), sino una obra en la que buena parte de los poemas han sufrido profundas correcciones.

9 Por lo que atañe a las reediciones, recuérdese que, en el mismo año de 1983, de modo paralelo a la publicación por parte de Bruguera, ve la luz también en Barcelona el volumen de Orbis Sonetos y canciones, que contiene la traducción de Crespo. Las reediciones de la traducción del poeta de Ciudad Real se han sucedido desde entonces en distintas editoriales madrileńas y barcelonesas y su título ha ido oscilando entre los dos mencionados. Así, en 1988, la colección Austral de Espasa Calpé lanza Sonetos y canciones y, en 1995, Alianza publica el Cancionero, reeditado en 2008.

${ }_{10}$ Esta es, con leves modificaciones, la lección de los Rvfque publican las versiones catalana y castellana. Si bien la obra de Desclot es posterior a la publicación de la edición del Cancionero al cuidado de Santagata (Petrarca 1996b), hay que tener en cuenta que, tal y como informa el traductor, su labor comenzó en 1994 (Petrarca 2016: 35). 
Los estudios que preceden a las versiones gallega y catalana son marcadamente menos amplios y ambos están firmados por los traductores. Así, el Cancioneiro de Cabana se abre con un «Limiar» de 23 páginas que se subdivide en «Vida de Francesco Petrarca» y «Sobre o Cancioneiro» (pp. 9-26), comentarios acerca de la nueva traducción (pp. 26-29) y bibliografía (pp. 30-32). Desclot, por su parte, abre su Cançoner con un aparato de 54 páginas: «Presentació» (pp. 9-40), en la última parte de la cual expone los principales rasgos de su traducción (pp. 35-39), y una cronología (pp. 42-63).

Como se puede observar, es en el prefacio o en sus confines donde el traductor recoge las reflexiones de las que se ha servido para elaborar su propia poética de la traducción, rasgo que encaja con la definición que Genette, en su completo estudio sobre los paratextos, dio de este segmento textual al definir el prefacio como «toute espèce de texte liminaire [...] consistant en un discours produit à propos du texte qui suit ou qui précède» (1987: 164) y, aún más, con la radical postura de Lejeune, que describió esta sección como la «frange du texte imprimé qui, en réalité, commande toute la lecture» (1975: 45).

Ahora bien, si deseamos seguir aplicando los presupuestos teóricos de Genette a los prefacios de las traducciones nos encontraremos con una encrucijada: ¿este tipo de prefacios habrían de considerarse como alógrafos o como autoriales? Dicho de otro modo, ¿tiene el traductor la potestad de atribuirse la propiedad del texto que está presentando o a través de estas páginas trata simplemente de describir la intervención que ha llevado a cabo sobre un patrimonio que le es ajeno? ${ }^{11}$.

La respuesta a este interrogante no es, desde luego, sencilla, si bien, de entrada, podemos afirmar que choca con los principios de la traducción cubierta según la concibió Juliane House ya a partir de los años setenta y tal y como la defendieron muchos otros traductólogos tras ella ${ }^{12}$. Del mismo modo, al menos por lo que

${ }^{11}$ El mismo estudioso no parece tan tajante (véase la cursiva que añadimos a la cita) con respecto a esta modalidad de prefacio al dedicarle, simplemente, esta somera observación: «En cas de traduction, la préface peut être [...] signée du traducteur. Le traducteur-préfacier peut éventuellement commenter, entre autres, sa propre traduction; sur ce point et en ce sens, sa préface cesse alors d'être allographe» (Genette 1987: 267). Al margen de esta exigua presencia en la obra del crítico galo, estamos totalmente de acuerdo con la afirmación de Letawe (2018), que lamenta que este tipo de paratexto haya gozado de tan escasa fortuna entre la crítica hasta el punto de que en la monografía que Luneau y Sant-Armand (2016) han consagrado a los prefacios no hay un solo epígrafe dedicado a esta modalidad.

12 Afirmaba House que «Der Übersetzer hat die Aufgabe, sich selbst hinter der Verwandlung des Originals zu verbergen» [«El traductor tiene el deber de ocultarse tras la transformación del original», la traducción es nuestra] (2002: 106). Recuérdese asimismo la frecuencia con la que se usa el cristal como metáfora de este fenómeno en ensayos acerca del papel del traductor. En este sentido, si Mounin pensaba que el ideal de todo traductor debía ser «Devenir un verre si transparent qu'on croie qu'il n'y a pas de verre» (1994: 74), la reveladora obra de Venuti acerca de la invisibilidad del traductor se abre con la rotunda aseveración de Shapiro según la cual «I see translation as the attempt to produce a text so transparent that it does not seem to be translated. A good translation is like a pane of glass. You only notice that it's there when there are little imperfections-scratches, bubbles. Ideally, there shouldn't be any. It should never call attention to itself» (Shapiro en Venuti 1995: 1). 
concierne a la traducción poética y, sobre todo, a la traducción de los clásicos de la poesía, tampoco es válida la afirmación de Letawe según la cual «Le cas où le traducteur-préfacier parle explicitement de son travail de traduction est très rare» (2018).

$\mathrm{Al}$ margen de la frecuencia de aparición que, según esta autora, tiene el prefacio escrito por el traductor, Letawe vierte una afirmación que enlaza con los interrogantes que más arriba formulamos, al aseverar que «même quand on leur donne la parole dans une préface, la plupart des traducteurs présentent l'œuvre traduite comme un philologue présenterait l'original» (2018). Con el objetivo de evaluar la validez de estas palabras y en aras de analizar los cuatro prefacios de la forma más eficiente posible por lo que atañe a nuestro objeto de estudio, rastrearemos en cada uno de ellos los juicios que los traductores, en tanto que autores del TM, emiten acerca de tres factores relevantes en este tipo de textos. En primer lugar, abordaremos las observaciones en torno a la rima y a su importancia en la traducción poética; en segundo lugar, nos ocuparemos de las reflexiones dedicadas a la lengua y al peso que posibles estructuras arcaizantes procedentes de la tradición petrarquista pudieran tener en el TM y, por último, analizaremos las reflexiones acerca de las notas como elementos destinados a aclarar las dificultades del TO.

\section{CONSIDERACIONES EN TORNO A LA RIMA}

El primer fenómeno que analizaremos orbitará en torno a las consideraciones que cada traductor presenta con respecto a la rima y a la importancia de su preservación en el TM. Tal vez este sea el terreno más pantanoso por lo que tiene que ver con las fronteras de la traducción intertemporal, pues la rima $-\mathrm{y}$, por consiguiente, su preservación- se puede valorar simplemente en términos estéticos, esto es, como un constituyente más del TO, o también en el sentido de lo que podríamos denominar una poética diacrónica, de acuerdo con la cual la rima sería un componente cultural imprescindible e imposible de desvincular de la cultura literaria que creó el TO. En contraste con esta cultura literaria, en el contexto de recepción y entre la audiencia meta, es perfectamente concebible la existencia de un texto poético que carezca de este elemento. En esta encrucijada, todos los traductores tienen que tomar partido por un bando, bien sea de manera implícita a través de la configuración de sus textos meta, bien sea de forma explícita en sus prefacios.

Para con este fenómeno, la postura de Ángel Crespo es rotunda, al afirmar:

Siguiendo nuestro método de siempre, que obedece a la convicción de que la traducción de las obras en verso no puede aspirar a ser completa, ni siquiera parcialmente fiel, si prescinde de los valores rítmicos y demás recursos formales del original, hemos tratado de respetar escrupulosamente tanto los esquemas estróficos del original como sus rimas -incluso en el caso de las internas- y, cuando ello ha sido posible, sus aliteraciones y demás rasgos estilísticos (1983: cXI).

Para el poeta de Ciudad Real, la rima es un constituyente esencial del texto poético; por ende, no se puede prescindir de ella en una traducción. En consonan- 
cia con esta postura teórica, los esquemas estróficos presentes en su traducción son impecables, incluso en aquellas composiciones en las que el TO se construye sobre procedimientos que conllevan algún tipo de dificultad en su traslación concreta al español. Este, por ejemplo, es el caso de aquellos versos que emplean terminaciones de rima cuyo equivalente directo en español ocasionaría palabras agudas, procedimiento proscrito en la poesía en nuestra lengua desde hace siglos ${ }^{13}$.

Cabana comparte la praxis de Crespo con respecto a la rima, de manera que aclara al lector que «a métrica e as rimas do orixinal se manteńen rigorosamente na tradución» y añade, de modo mucho más radical: «Creo [...] que unha tradución métrica dun poeta coma Petrarca tende a ser máis fiel ca unha tradución literal, polo menos en principio. Unha tradución fascinada por la literalidade non produce poemas» (2012: 27).

Desclot comparte este modus traducendi si bien, tal vez porque da por sentada la necesidad de la rima cuando se traduce a un autor como el aretino, no emite juicio alguno al respecto, limitándose a afirmar, en términos generales, «en tot moment he seguit el text de Petrarca tan de prop com he sabut, lingüísticament i formalment” (2016: 38) y, en efecto, cabe destacar también en la traducción catalana un respeto encomiable hacia las formas métricas e, incluso, hacia la disposición de la rima, que se respeta en la inmensa mayoría de los casos, independientemente de la dificultad de la misma ${ }^{14}$.

Cortines, en cambio, toma una posición radicalmente distinta a las hasta aquí expuestas y defendidas, con palabras y con hechos, por los otros tres traductores. El poeta sevillano afirma rotundamente: «no usé la rima porque este procedimiento siempre resultó ajeno a mi modo de utilizar la lengua poética, entre otras razones por no considerarlo, salvo excepciones, consustancial y decisivo» (1989a: 10) y, algo más adelante, recapitula especificando que uno de los criterios para su traducción ha sido «no sólo [la] ausencia de rimas, sino [la] exclusión de éstas para que no interrumpieran esa otra musicalidad del verso blanco" ${ }^{15}$ (1989a: 12).

${ }^{13}$ Con respecto a la teorización de este fenómeno, véase Rico (1983). En las ocasiones en las que Crespo se enfrenta a esta dificultad, se suele decantar por manipular el contenido del verso cambiando su orden y modificando los elementos conclusivos del mismo. Hallamos un ejemplo de esta praxis ya desde el primer poema del Cancionero, cuya rima B se construye sobre la terminación italiana -ore. Así, si en el TO se lee «di quei sospiri ond'io nudriva'l core [=corazón] / in sul mio primo giovenile errore [=error] [...] fra le vane speranze e'l van dolore [=dolor] / ove sia chi per prova intenda amore [=amor]» (vv. 2-3; 6-7), la versión de Crespo se sirve de la posposición del verbo al final del verso y de la rima desinencial que permite la terminación del imperfecto en los verbos de la primera conjugación: «oís del suspirar que me alimentaba / al joven corazón que desvariaba [...] cuando a esperanzas vanas me entregaba / si alguno de saber de amor se alaba» (vv. 2-3; 6-7).

${ }^{14}$ Uno de los escasos momentos en los que esto no sucede -sin afectar en lo más mínimo a la calidad formal del TM- es en el congedo de determinadas sextinas (por ejemplo, en Rvf 239), donde la sílaba en la que aparecen las palabras-rima no coincide con la del TO.

${ }_{15}$ Aunque no se trate de rima en sentido estricto, el único tipo de estrofa donde Cortines adopta plenamente el esquema de repeticiones al final de verso de Petrarca es la sextina. En estos casos, el traductor se sirve de las mismas seis palabras a lo largo de las seis estrofas y del congedo que aparecen en el esquema del TO. 
Estos juicios para con la relevancia de las rimas sitúan a las dos traducciones castellanas en posiciones antitéticas: si para Crespo la traducción poética es simplemente imposible sin un respeto pleno e integral hacia los componentes formales y rítmicos del TO, Cortines considera la rima como un elemento que, lejos de contribuir a la calidad o a la poeticidad del TM, lo perjudica. Es más, el poeta sevillano incluye en su prefacio un interesante juicio que contrapone su versión a la del traductor de Ciudad Real, al confirmar al lector que, mientras se hallaba inmerso en su traslación del Cancionero, «apareció la versión de Ángel Crespo [...] que se orientaba en direcciones que no eran las por mí perseguidas» y concluye que «no había, pues, motivos para no culminar lo ya emprendido» (1989a: 12).

Más allá del contraste entre las traducciones castellanas, esta oposición también puede rastrearse si se opone la versión de Cortines a las traducciones gallega y catalana, que vieron la luz con posterioridad.

Es cierto que, en cierta medida, la pérdida que la rima pueda acarrear en la traducción del sevillano se ve mitigada por el hecho de que, como se ha dicho, la edición de Cátedra es bilingüe y el patrón de rima italiana es totalmente transparente para el lector hispanófono, independientemente del conocimiento que este tenga de la lengua de Petrarca. No obstante, cabe recordar que las ediciones de Curuxa y de Proa también muestran la misma disposición y ello no es óbice para que los esquemas estróficos y rítmicos del TO sigan presentes en el $\mathrm{TM}^{16}$.

Una vez abordada la cuestión de la rima, trataremos diversos componentes del texto poético cuya traducción o adaptación comporta una serie de cuestiones relacionadas de forma más directa con las problemáticas que conlleva la traducción intertemporal y con las estrategias mediante las cuales estos obstáculos se pueden solventar. Los elementos analizados a continuación son aquellos en los que el paso del tiempo y, por ende, lo que podríamos denominar el desfase cultural que padece el TO se pueden presentar con una mayor incidencia a ojos de la audiencia meta, luego será con estos componentes con los que el traductor deberá ser especialmente hábil a la hora de ejercer su función de guía del lector hodierno.

\section{LA LENGUA Y EL PESO DE LA TRADICIÓN POÉTICA}

Tal vez el elemento cuya variación se observa de modo más palmario en textos que pertenecen a un pasado remoto sea la lengua. Con respecto a esta, el traductor se encuentra en una encrucijada, que es particularmente conflictiva en casos como el que nos ocupa: habiendo dado la imitación petrarquista tan excelsos frutos en la península ibérica, ¿los traductores deberían dejar que la lengua de estos líricos

16 En este sentido, cabe mencionar que Desclot confiesa que, en los albores de su trabajo, en mayo de 1995, mostró «aquelles primeres traduccions al poeta Ángel Crespo [...] i així va ser com ell em va incitar a traduir tot el llibre» (2016: 35). Desde luego, el poeta catalán siguió unos derroteros que, por lo que concierne al respeto de los patrones estilísticos, tenían mucho que ver con los transitados por Crespo más de una década antes del encuentro referido. 
ibéricos permease sus textos o habrían de evitarlo? ${ }^{17}$. Tanto a través del modus traducendi como de la reflexión teórica del prefacio, los cuatro traductores analizados se pronuncian adoptando distintas posturas en relación con este aspecto.

El que afronta el peso de la tradición petrarquista sobre la lengua de modo más directo es Crespo, al afirmar que

A ningún lector se le escapará que el [lenguaje] empleado por nosotros trata de aproximarse -sin incurrir en arcaísmos-a los de los grandes líricos castellanos de los siglos XVI y xviI, en muchos de los cuales la huella de Petrarca es, por supuesto, manifiesta. No obstante lo cual [...], hemos procurado no incurrir en arcaísmos $-s i$ alguno hay, es mera licencia poética inspirada, bien por la necesidad, bien por un deseo de apelar a la circunstancia histórica- tanto gramaticales como de léxico. Algunos de los que hay, sin embargo, obedecen a la intención de hacernos eco de ciertos preciosismos del original (1983: CXI-CXII).

En efecto, la traducción de Crespo se mueve en ese plano de ambivalencia lingüística y estilística que el autor explica en estas líneas: en términos generales, se sirve de un registro que -si bien no puede definirse sino como poético, con todo lo que ello implica- no es del todo ajeno a la lengua viva de nuestro tiempo. No obstante, hay ocasiones en las que el traductor introduce elementos cuyo arcaísmo remite de manera notable a ese modus scribendi que los huérfanos ibéricos de Petrarca utilizaron en el Siglo de Oro y que, dicho sea de paso, ayuda a Crespo a resolver problemas relacionados con el cómputo silábico, la sonoridad o la acentuación de determinados versos o composiciones ${ }^{18}$.

Más radical aún que la postura del traductor de Ciudad Real, aunque circunscrita a unas cuantas elecciones léxicas, es la praxis de Cabana, que opta por

Adoptar sistematicamente, sobre todo por comenencia de rima, dous substantivos antigos hoxe ausentes da fala e da escrita ordinaria. Un deles é cór por corazón, usado con pouca frecuencia relativa na nosa lírica medieval, con bastante na prosa

${ }^{17}$ De las cuatro versiones aquí estudiadas, por motivos históricos, podría ser el traductor gallego el único que se mantuviese inmune a esta reflexión o esta encrucijada por el simple hecho de que la penetración del aretino en la lírica ibérica se produjo cuando la cultura gallega se encontraba sometida a la castellana. Con todo, cabe recordar las elevadas cotas que alcanzó la lírica galaicoportuguesa y, en cierto modo, la afinidad de materias tratadas entre esta y la poesía petrarquista. En la medida en que este paralelismo podría justificar la adopción de Cabana de caudal léxico arcaico, no creemos que el traductor gallego se sitúe realmente en una tesitura que diverja en demasía de la esbozada para con las otras dos lenguas.

${ }_{18}$ Entre otros muchos, véanse los siguientes usos arcaicos (marcados con cursiva) que hacen que el TM sea más respetuoso con el TO de lo que hubiese sido el empleo de términos o estructuras más frecuentes en el español actual: "y a Jove, más que a Marte, dio clemencia» (4, 4); «Cabe los cerros do, por vez primera» $(8,1)$; «El sucesor de Carlos, que la coma» $(27,1)$; «¿Qué haces tú, cuitado?» (68, 3); «A Julio César la honorable testa» $(102,2)$; «Mientras el dolor nuevo la encocora» (103, 9); «Oh Sol, la única fronda por mí amada» $(188,1)$; «Caro señor, de mí el recuerdo tira» $(266,1)$, etc. 
notarial, e nunca na histórica. [...] O outro substantivo é frume, río, que algunha vez tamén se le flume nos nosos textos antigos (2012: 27-28).

Pero estos dos sustantivos distan de ser los únicos elementos arcaicos, cuando no artificiales, usados por el traductor en su versión:

Tamén emprego con frecuencia o vello pronome indefinido outrén, moi xeitoso pra anosar o italiano altrui, e algunhas veces non son capaz de resistir as vantaxes que o perdido adverbio allur ten pra significar noutra parte.

O latinismo lauro por loureiro é paralelo ó orixinal, no que predomina sobre o patrimonial alloro. [...] Algunhas veces non receo empregar formas reducidas ben testemuñadas na fala ou na literatura do tipo espranza, esprito, praz ou quer; que non creo necesario marcar na escrita, pois no estado actual da nosa lingua literaria estas variantes son xa perfectamente recońecibles como tales. [...] Pola contra, algunhas veces escribo ó xeito tradicional ialba ou ialma, uso proscrito hoxe -e con razón- da prosa, pero que no verso marca moito ben a pronuncia métrica desexada (2012: 28).

En definitiva, desde el punto de vista léxico, Cabana ve lícito recurrir a un lenguaje que podríamos calificar como una suerte de pastiche en el que se combinan elementos de naturaleza cronológica, diafásica e incluso diastrática diversa y que buscan facilitar la composición del TM. Entre estos constituyentes del caudal léxico tan heterogéneos entre sí, se da cabida a elecciones provenientes de sistemas que van desde la tradición literaria galaicoportuguesa medieval hasta el gallego oral. Con estos elementos, el traductor logra crear una especie de koiné literaria materializada en un TM que, a fin de cuentas, no adolece en absoluto de haber surgido en una cultura en la que la influencia directa de Petrarca solo puede calificarse, con generosidad, de marginal ${ }^{19}$.

No hallamos en los preliminares de Cortines una referencia tan explícita a la cuestión lingüística y a la problemática que de ella se deriva como en los prefacios de Crespo y Cabana. Sin embargo, el poeta sevillano confiesa que una de sus principales preocupaciones cuando emprendió la traducción que nos presenta fue la de «buscar las palabras precisas» (1989a: 10). Llega esta confidencia mientras pasa revista, de forma somera, a aquellos autores áureos que afrontaron la traducción de los textos petrarquescos, desde la versión parcial de los sonetos y canciones de Salomón Usque hasta la traducción de los Triunfos de Hernando de Hoces, y, en términos generales, no vuelve a acometer el análisis de las cuestiones lingüísticas inherentes a la traducción en todo su prólogo. Decimos que Cortines no torna sobre este asunto bajo un prisma general puesto que, discurriendo acerca de la particularidad que conlleva la traslación de las sextinas y de lo arduo de conservar sus palabras-rima según el esquema de rotación que el original prevé, especifica que

19 El peso que las traducciones de Cabana y sus recuperaciones léxicas ha tenido sobre la lengua poética gallega actual ya ha sido puesto de manifiesto por parte de Barreiro Comedeiro y Rodríguez Ruibal (2003). 
La tentación de emplear, por ejemplo, lauro en lugar de laurel, aunque el primero figurase como admitido en el Diccionario de la Real Academia, no me parecía la solución más adecuada por estimar que un término tan clave en el universo del Cancionero no debería aparecer con sombras de arcaísmo (1989a: 13).

Con respecto a esta afirmación, cabe destacar dos factores. En primer lugar, concordamos plenamente con el traductor en el hecho de que la elección del equivalente para el término "lauro» conlleva una dificultad mayúscula en nuestra lengua, puesto que el lema de uso más natural, «laurel», es un sustantivo agudo, con lo que diverge del patrón de sonoridad del original italiano. Asimismo, compartimos la necesidad, a pesar de esta disimetría fónica, de que un término que resulta clave tanto en el terreno simbólico como en el meramente semántico de los Rvfdebería ser transparente para el lector hispanohablante. Sin embargo, para solventar dificultades como esta, hay ocasiones en las que Cortines opta por esquivar el término conflictivo en cuestión neutralizándolo con generalizaciones que sacrifican parte del contenido del TM. Por citar un caso concreto en un contexto relevante, esto es lo que sucede en 197, 1 donde el «verde lauro» se transforma en unas genéricas e indeterminadas «verdes ramas» ${ }^{20}$.

En segundo lugar, la postura de Cortines de evitar a toda costa los arcaísmos enlaza, a nuestro juicio, con su ya señalada voluntad de huir de la constricción que supone la rima por no considerarla un elemento determinante o definitorio del texto poético (1989a: 10). De ambos pensamientos se puede inferir que la concepción, al menos en términos formales, que el poeta tiene de la poesía es claramente contemporánea. En este sentido, no se puede dejar de alabar su coherencia: si, en efecto, Cortines concibe su versión de acuerdo con los parámetros del verso blanco, a este tipo de metro no le podía ser connatural en castellano un léxico arcaizante, por lo que la actitud del traductor de rehuir de la herencia petrarquista áurea es totalmente lógica.

Como portavoz de una cultura literaria que posee esta misma tradición de la que la literatura castellana es deudora, Desclot se pronuncia de un modo más explícito que Cortines sobre la imitación o la adopción de elementos arcaizantes en su traducción del siguiente modo:

Vull remarcar que no he pretès fer parlar Petrarca en català, sinó que més aviat he fet per manera de deixar-lo parlar en català. En altres paraules: he mirat de no imposar-li res, tret de la llengua (ben mirat, doncs, quasi tot!). No he volgut fer-ne

${ }^{20}$ A modo de ejemplo de esta praxis, citamos este verso en concreto puesto que el soneto 197 es el penúltimo del denominado «Ciclo de l'aura» (194, 196-198), un conjunto de cuatro sonetos que se abren con la invocación a la amada. En todo el conjunto, las distintas modalidades de senhal que Petrarca operó para tratar de ocultar el nombre de la dama cobran una importancia determinante, pero es precisamente en el soneto 197 donde encontramos, en posición altamente simbólica tres de ellos: «L'aura» inaugurando el poema, «lauro» cerrando el primer verso y «l'auro» concluyendo el segundo cuarteto. Para más información acerca de la importancia del senhal en la interpretación de esta composición, remitimos a Segre (1983). 
un poeta del segle XxI, perquè el més gran poeta del segle XIV ja és un poeta d'avui per ell mateix, però tampoc no he volgut fer-ne un poeta català medieval (2016: 36).

De estas palabras parece traslucir una postura opuesta a las praxis de Crespo y Cabana, pero también a la de Cortines, que se manifiesta igualmente en el modus traducendi del catalán: la lengua en la que se expresará el Petrarca de Desclot es una lengua natural, quizás podríamos decir que se trata de aquella cuya audiencia meta percibe como la más natural de las cuatro. En efecto, con la única salvedad del uso de ciertos términos con la acepción trecentesca exigible en el contexto de los $R v f^{21}$, Desclot huye en su lengua poética del uso de lemas artificiales o arcaicos que encorseten la voz del aretino en moldes que le son ajenos. Es cierto que, a diferencia de la herramienta de trabajo de los otros tres traductores, la sonoridad y el caudal léxico del catalán son más afines al italiano que estos mismos aspectos del castellano o del gallego, pero, en cualquier caso, hay que alabar la lengua de Desclot, tanto por su fidelidad al TO como por su belleza, armonía, equilibrio y coherencia.

\section{LAS NOTAS AL TEXTO COMO MECANISMO EXEGÉTICO}

Tras la lengua o, mejor dicho, desde una perspectiva más amplia que las meras consideraciones lingüísticas, es la cultura el elemento en el que el desfase del TO presenta mayores dificultades para la audiencia contemporánea y es en aras de solventar esta dificultad para lo que el traductor intertemporal tiene que esforzarse en mayor medida. En efecto, si hemos visto que la lengua podía resultar arcaizante y, por ende, remitir a un contexto lejano o extraño al lector, los peligros que se derivan de las alusiones a cualquier tipo de referente cultural presente en el texto son incluso mayores.

Puesto que los elementos culturales que atañen a la forma del TO inciden en la inmensa mayoría de los casos sobre la métrica y el lenguaje, elementos ya analizados, nos ocuparemos ahora de la problemática que la esfera cultural implica para con el contenido de las composiciones y, en relación con ella, abordaremos el juicio que cada uno de los traductores emite acerca de las notas, consideradas estas como espacio de exégesis o de autoexégesis necesario para la comprensión íntegra de determinados pasajes de la obra ${ }^{22}$.

${ }^{21}$ Con respecto a estas excepciones, puntualiza el traductor que "paraules com virtut, gentil o salut, per dir-ne només tres, s'han de llegir habitualment en el sentit que tenien en la nostra llengua clàssica» (2016: 37).

${ }^{22}$ Utilizamos esta definición de nota puesto que, al menos por lo que respecta al corpus estudiado, la ofrecida por Genette se nos antoja demasiado laxa: «Une note est un énoncé de longueur variable (un mot suffit) relatif à un segment plus ou moins déterminé du texte, et disposé soit en regard soit en référence à ce segment» (1987: 321). Múltiples son los juicios vertidos acerca de estos paratextos, tanto en su vertiente exegética (cabe recordar la célebre descripción de Alain según la cual "La note c'est le médiocre qui s'attache au beau», 1954: 99) como traductológica, por ejemplo, según Eco, la nota al pie es la prueba de la derrota del traductor (2003: 95). 
Con respecto a este paratexto, nos parece interesante recordar lo que Genette afirmó en términos generales e introductorios sobre las notas:

Cet enjeu stratégique [su posición] compensera peut-être ce que comporte inévitablement de décevant un «genre» dont les manifestations sont par définition ponctuelles, morcelées, comme pulvérulentes, pour ne pas dire poussiéreuses, et souvent si étroitement relatives à tel détail de tel texte qu'elles n'ont pour ainsi dire aucune signification autonome (1987: 321).

Repetimos, según la concepción del estudioso francés, las notas remiten a un género cuyas manifestaciones son, por definición, puntuales, parceladas, pulverulentas y, a menudo, tan estrechamente ligadas a determinados detalles del texto al que se refieren que carecen de significado autónomo.

La opinión -y la praxis- de Crespo concuerdan plenamente con esta esfera. En su prefacio, el poeta dice que, puesto que su objetivo ha sido el de ofrecer una versión del Cancionero que permita una lectura poética,

Hemos reducido casi al mínimo el número de notas, las cuales se refieren, en su mayor parte, y como el lector podrá comprobar fácilmente, al esclarecimiento de pasajes oscuros, o tenidos por tales, al significado, en el contexto petrarquesco, de determinadas palabras, a la identidad de algunos personajes, reales o mitológicos, citados en los versos y, más raramente, a la fecha de alguna rima o a las influencias poéticas o fuentes ideológicas de varias de ellas. Las notas de las dos últimas categorías no quieren sino ser ejemplos de lo que podría haber sido hecho para mostrar las relaciones de la cultura de Petrarca con la tradición clásica romana y con las más próximas de la escuela trovadoresca y el estilnovismo, a las cuales se hace referencia en esta introducción (1983: CXII).

En efecto, las notas de Crespo tienen como objetivo principal la aclaración o la glosa de elementos puntuales contenidos en el interior del texto poético y, por ello, suelen aparecer junto a sintagmas o conceptos que hacen referencia a ámbitos o interpretaciones que el lector actual probablemente no conozca. En contraposición con esta tónica, son raras las notas que se refieren al conjunto de la composición y, cuando aparecen, su presencia se justifica sobre la base de la importancia de conocer este dato para interpretar correctamente el contenido del poema en cuestión ${ }^{23}$. En cualquier caso, cabe destacar que la extensión de las notas en la versión del poeta de Ciudad Real es en todo momento contenida y, en la mayor parte de las ocasiones, no va más allá de una sola línea.

Comparte la voluntad y la opinión de Crespo Jacobo Cortines, que, en sus «Preliminares», informa de lo siguiente:

23 Véanse a estos efectos, entre otras, las notas a los sonetos 112 y 113 , dirigidos a Sennuccio del Bene, o a 114, primero de los sonetos babilónicos contra la corrupción en la corte papal de Aviñón. 
En cuanto a las notas sólo tengo que decir que son deliberadamente exiguas, pues una obra como la de Petrarca, de tan secular tradición de comentaristas, reclamaría para sí un gran aparato que exigiría la competencia de especialistas. Como no es este el caso, me he limitado a poner únicamente aquellas que he creído imprescindibles teniendo en cuenta la variedad de posibles lectores. Son notas más aclaratorias y explicativas que de interpretación, aspecto este que hemos evitado para no condicionar a ningún lector (1989a: 14). exegética:

$\mathrm{Y}$ añade un interesante matiz por lo que concierne al aparato con finalidad

El texto poético habla por sí mismo, y el de Petrarca es elocuente, aunque en ocasiones resulte difícil. No se culpe, pues, siempre a la torpeza del traductor por la dificultad que el lector hallare en algunos pasajes que requieren una especial atención o relectura. La dificultad es a veces un procedimiento expresivo que no tiene por qué exigir necesariamente continuas notas a pie de página (1989a: 14).

En consonancia con este presupuesto teórico, la de Cortines es la traducción que va acompañada por un menor número de notas de las cuatro analizadas. Por lo que se refiere a su formato, comparte con la edición de Crespo el hecho de que se recogen aclaraciones de carácter puntual que muy rara vez superan la línea de extensión y, por consiguiente, también el aparato de notas de esta versión podría definirse, con las palabras de Genette, como puntual, parcelado y dependiente del texto literario ${ }^{24}$.

Mucho más prolijo en sus notas es Miquel Desclot ${ }^{25}$, que justifica este rasgo en el prólogo a su traducción al afirmar:

Com que en tot moment he seguit el text de Petrarca tan de prop com he sabut, lingüísticament i formalment, el meu text necessita tantes notes aclaridores com el seu, o més. El lector trobarà, doncs, al final del llibre l'aparat de notes que he preparat per facilitar-li la comprensió de cada poesia. [...] Aquestes notes han estat pensades només per orientar i aclarir la lectura allà on calgui, i per això he procurat que fossin breus però alhora suficients. He evitat de carregar-les amb informació complementària, com ara la precisió de les fonts que els erudits han identificat per a cada passatge (2016: 38).

De las cuatro ediciones estudiadas, a Desclot cabe otorgarle el mérito de ser el único traductor que ańade notas a todas y a cada una de las composiciones

${ }^{24}$ A diferencia de lo que sucede en el caso de Crespo, en la edición de Cátedra, tal vez con el objetivo de no incidir gráficamente en el texto poético, no encontramos números voladizos que remitan al pie de página. Las notas aparecen precedidas por un asterisco en aquellos casos en los que pretenden contextualizar el conjunto de la composición o haciendo referencia al número del verso al que se refieren cuando persiguen aclarar una cuestión puntual.

${ }^{25}$ Como en el caso de Cabana, que abordaremos a continuación, las notas en la edición de Proa aparecen al final de la obra y no a pie de página. 
que traduce; además, por lo general, suelen ser bastante detalladas, pero, incluso en aquellos casos de extensión más comedida, tratan de manera certera los elementos clave de cada poema que el lector hodierno puede percibir como más arduos. Estas notas se abren siempre con una breve contextualización acerca de la circunstancia narrada en cada poema y, tras ella, pasan revista a las principales dificultades ocultas en cada verso que, en no pocas ocasiones, se desgranan con todo detalle trayendo a colación un ingente saber filológico y literario que, lejos de aparecer como mero intelectualismo ornamental, es de gran utilidad para insertar a la audiencia en el contexto cultural en que surgió de manera específica cada microtexto. Por citar algunos casos concretos, véase el detalle con el que el traductor aborda los problemas que pueden derivar de las composiciones 105, 206, 264, 360 o 366.

No sabemos hasta qué punto se puede concordar con el traductor acerca de la «brevedad» de las notas que aporta (que se extienden durante 70 páginas). No obstante, es cierto que cuando hablamos de los $R v f \mathrm{y}$ de las dificultades que conllevan, cualquier extensión ha de considerarse limitada si se pretende, como afirma Desclot, que las aclaraciones de lectura sean «suficientes».

Si calificamos de rigurosa la labor de Desclot para con las notas, no podemos sino describir como detallado, minucioso y, en ocasiones, titánico el trabajo de Cabana que, plenamente consciente de ello, informa de lo siguiente:

As notas que con certa abundancia pońo ó final do libro están elaboradas a partir de tantas fontes -non sen algunha pequena cousa da propia minerva- que sería longo de máis poñer aquí unha relación circunstanciada. A maior parte delas son tributarias, xaora, das edicións que cito na bibliografía. Ás veces non me retraerei de meter algunha digresión ou información que, aínda sen ser esencial pró asunto, me pareza interesante ou divertida, pois estou case seguro de que o lector -mon semblable, mon frère- se divertirá tamén onde eu me divertín ${ }^{26}$ (2012: 28).

A diferencia de Desclot, Cabana no glosa todas las composiciones del Cancionero, si bien sus notas ocupan un apéndice de 74 páginas con un tamaño de letra inferior al de la versión catalana y en un formato ligeramente de mayor tamaño. El traductor gallego lleva a cabo en esta sección un análisis de determinados poemas que aborda lo cultural, lo histórico, lo hermenéutico y lo ecdótico ofreciendo nume-

${ }^{26}$ Cabana dedica otro párrafo más de su prefacio (a nuestro juicio, mucho más discutible que el anterior) a las notas incluidas en su versión y, más concretamente, a las numerosas fuentes literarias que en ellas se dan cita: «Se ese hipotético e desexado lector repara nas referencias literarias que anotamos -nada exhaustivamente, pois ás veces parécenos que tamén se cita moito por citarquizabes lle chame a atención o predominio dos ecos textuais da literatura clásica latina sobre os da poesía dos trobadores. A nós tamén nola chama, pois no espírito sucede xusto ó revés: a poesía amorosa do Petrarca ten bastante máis que ver coa complexa sentimentalidade occitana ca co erotismo grecorromano, certamente ben refinado ás veces, pero en substancia máis simple e máis directo cá fin amors. Chámanos a atención, pero non nos estraña: sendo quen era o Petrarca e lendo o que lía, esta contradición é só aparente, ou onde non é a contradición da súa propia vida e da súa propia ideoloxía» (2012: 29). 
rosos datos que, en algunos casos, sobrepasan incluso los límites de lo que estamos acostumbrados a ver en las ediciones italianas del aretino. Si bien los comentarios a las distintas composiciones carecen de una estructura homogénea, pues en ocasiones el traductor comenta las circunstancias del poema en su conjunto y otras veces aborda directamente las dificultades de cada verso, es digno de alabanza lo pormenorizado del análisis de 29, 50, 102, 135, 206, 263, 360 o $366^{27}$.

Tal es el rigor que el traductor gallego pone en la confección de sus notas que resulta difícil aplicar la definición de Genette al aparato publicado por Curuxa, puesto que este no es, en muchos casos, ni puntual ni parcelado ni, frecuentemente, se halla tan íntimamente vinculado al texto literario en cuestión que carezca de significado autónomo. Si tomamos como base, por citar un ejemplo concreto pero no aislado, la nota a la canción 206, «S'i'l dissi mai, ch'i' vegna in odio a quella» (2012: 626-627), observamos un profundo comentario acerca de los trovadores galaicoportugueses con producción de temática o tono afines a esta composición petrarquesca que podría formar parte perfectamente de un estudio consagrado a la poesía trovadoresca o al motivo del escondig en la lírica medieval. Sin embargo, la mayor parte de las observaciones que contiene esta entrada de carácter enciclopédico -al igual que sucede con otras que comparten este enfoque- solo guarda relación de manera circunstancial con el microtexto que sirve de punto de partida para la reflexión.

Es cierto que tal cosa no debe verse, en términos absolutos, como una mácula para el trabajo de Cabana, sino como la materialización de la voluntad del traductor -convertido aquí en filólogo petrarquista o de motivos petrarquescos- de presentar en paralelo los textos de uno de los mayores poetas de todos los tiempos con los de la mayor escuela lírica que surgió en territorio gallego.

Para concluir la sección dedicada a las notas, creemos que hay una particularidad de cada edición que tiene que ser considerada y analizada en paralelo a la presencia de estos elementos y, sobre todo, a su carácter exegético o de contextualización más general en cada obra: nos referimos a la profundidad con la que en cada una de las cuatro ediciones se abordan los datos biográficos y culturales que atañen a Petrarca y a su producción en el prólogo o en la introducción. Si cruzamos la extensión que en cada volumen ocupan las notas y el alcance de las mismas con lo detallado de la introducción, nos damos cuenta de que son precisamente aquellas ediciones en las que el prólogo tenía unas dimensiones más comedidas donde las notas aparecen con mayor profusión y mayor alcance, al no aparecer en relación con pasajes aislados, sino, en ocasiones, referidas a composiciones enteras o, incluso, a fenómenos que trascienden las composiciones mismas.

Este es el caso de las traducciones gallega y catalana. En la primera de ellas, hallamos una introducción que se ocupa, stricto sensu, de Petrarca durante 17 páginas y unas notas finales de 74. La edición de Proa, por su parte, presenta un prólogo

${ }^{27}$ Esta praxis se mantiene con el comentario de las rimas dispersas que Cabana incluye en su edición. Véanse, en este sentido, por ejemplo, las notas a 16, «Sì come il padre del folle Fetonte», o 28, "Quel c’ha nostra natura in sé più degno». 
de 25 páginas de extensión en el que se discurre sobre la vida y la obra del aretino y unas notas finales de 70 . El alcance de estos prólogos dista de la profundidad que se deriva del más de centenar de páginas que el mismo Crespo y Nicholas Mann firman en las dos ediciones castellanas ${ }^{28}$.

\section{HACIA UNAS CONCLUSIONES}

Llegados a este punto y para presentar una síntesis que nos sirva como conclusión, cabe recordar la célebre dicotomía que Schleiermacher atribuyó al traductor por lo que respecta a su comportamiento con respecto al TO y a sus componentes culturales. Afirmaba el filólogo de Breslavia: «Entweder der Uebersezer läßt den Schriftsteller möglichst in Ruhe, und bewegt den Leser ihm entgegen; oder er läßt den Leser möglichst in Ruhe und bewegt den Schriftsteller ihm entgegen ${ }^{29}$ (en Störig 1963: 5).

Combinando los distintos aspectos analizados en las cuatro traducciones objeto de estudio se pueden rastrear ejemplos de ambos modos de proceder.

En la medida en que en la configuración de sus traducciones ponen un mayor énfasis en el mantenimiento de las formas propias del TO, Crespo y Cabana son los autores de las versiones que optan por la primera postura, es decir, la que consiste en realizar las menores modificaciones y, sobre todo, las menores modernizaciones posibles sobre el texto en aras de preservar su esencia con el mayor celo para ofrecérselo al lector hodierno en el estado más original que la lengua meta permite. En consonancia con la defensa de esta postura, ambos traductores no titubean en entretejer sus composiciones con elementos léxicos o estructurales pertenecientes a un estado de la lengua que está en desuso si con ello recuperan algunos de los matices de sonoridad o algunas de las imágenes presentes en el texto de Petrarca.

Consecuencia directa de este celo conservador es, a nuestro juicio, la necesidad que ambos autores sienten de contextualizar histórica, cultural y literariamente el texto que presentan en sus respectivas ediciones. Así, Crespo firma una extensa introducción que, como ya se ha referido (vid. nota 28 ), posee una carga teórica y exegética que el mismo autor pone en relación con las notas al texto propiamente dichas. Cabana, por su parte, acompaña su traducción de un aparato de notas cuya profundidad trasciende las meras necesidades de contextualización y aclaración de la versión que presenta para justificar su relación con una tradición lírica bien definida y la coherencia de sus alusiones hacia ella.

${ }^{28}$ Como puede apreciarse en una de las citas que hemos reproducido con anterioridad, Crespo, consciente de la interrelación entre su prólogo y sus notas, informa al lector de que estas últimas están desprovistas de alusiones a las fuentes de Petrarca, «a las cuales se hace referencia en esta introducción» (1983: CXII).

${ }^{29}$ «O el traductor deja al escritor lo más tranquilo posible y mueve al lector hacia él, o deja al lector lo más tranquilo posible y mueve al escritor hacia él», la traducción es nuestra. 
En contraste con esta postura, la traducción de Cortines podría decirse el perfecto ejemplo de la praxis que persigue aproximar la obra al lector actual y el poeta sevillano lo admite sin recelo alguno sirviéndose de la paráfrasis que Ortega y Gasset realizó a la cita de Schleiermacher más arriba expuesta:

Si como recuerda Ortega citando a Schleiermacher: «la versión es un movimiento que puede intentarse en dos direcciones opuestas: o se trae el autor al lenguaje del lector o se lleva el lector al lenguaje del autor», está claro que yo había optado por lo primero, aunque esto sea más una imitación o paráfrasis del texto original que una traducción (1989a: 9).

El proceso de actualización de los $R v f$ del que Cortines se sirve en su traslación, que se puede observar principalmente en los citados aspectos lingüístico y métrico-rítmico, presenta al lector una versión del Cancionero que, lejos de estar simplificada, contiene toda la complejidad que le es inherente, pero que la audiencia meta sentirá como formalmente más cercana. Quizás, precisamente por este efecto, Cortines es coherentemente parco en notas y en aclaraciones exegéticas o hermenéuticas ${ }^{30}$ en su convicción de que no desea "condicionar a ningún lector [...] porque el Petrarca que aquí aparece es el que yo he leído y experimentado y ha de ser diferente del que han visto y han de ver otros» (1989a: 14).

En un terreno intermedio entre ambas tendencias se encuentra la traducción catalana de Miquel Desclot. Este texto es difícil de clasificar con respecto a la dicotomía de Schleiermacher, y esto se debe, en un cierto modo, a que comparte características de ambas tendencias. Tal vez, en términos meramente lingüísticos debido a la cercanía de la lengua origen a la lengua meta -pero, sin duda alguna, no solamente por ello-, en lo que atañe al plano formal no se puede afirmar que Desclot ofrezca una versión del aretino que pretenda acercarse al lector o, mejor dicho, no se trata de una versión que al acercarse al lector se aleje del autor ni sacrifique algunos de sus componentes principales. Así, el texto del poeta catalán es estrófica y lingüísticamente impecable tanto si se analiza desde la óptica de la fidelidad al TO como si se observa por lo que concierne a la naturalidad para con la audiencia meta. En este sentido, tal vez podría considerarse como la materialización que prueba que la poesía no es tan intraducible como algunos poetas y teóricos de la traducción se han afanado en predicar o, cuando menos, podríamos decir que la traducción de Desclot prueba que las pérdidas que un texto poético sufre en un proceso de traslación lingüística no tienen que comprometer ni su forma, ni su significado, ni tampoco las evidencias que lo anclan a un determinado contexto literario y cultural.

Para concluir, retomamos dos de las cuestiones con las que abrimos este análisis. En primer lugar, por lo que respecta a la afirmación vertida por Letawe (2018) según la cual, cuando los traductores toman la palabra para presentar sus obras, las describen con la misma asepsia con que un filólogo presentaría el original, queda

${ }^{30}$ Recuérdese que la introducción de esta edición es la única de las cuatro que no está firmada por el traductor de la obra. 
probado que, por lo que concierne al corpus analizado, la praxis es justo la contraria. Así pues, los traductores no escatiman en confesar al lector inquietudes, reflexiones y vivencias de naturaleza estrictamente personal y subjetiva que remiten a su propia experiencia de traducción y de apropiación del $\mathrm{TO}^{31}$.

Esta apropiación constituye un elemento fácilmente rastreable en los cuatro prólogos y, en ocasiones, incluso más allá de estos paratextos. En efecto, el hecho de que traducir a Petrarca ha sido algo más que un trabajo se puede observar en la fruición y la conciencia con las que Cortines, Cabana y Desclot revisaron y corrigieron sus primeras versiones del aretino, en ocasiones tras haber aparecido publicadas de forma parcial ${ }^{32}$ o total ${ }^{33}$. Otra prueba irrefutable de esta profunda huella que el aretino deja entre sus traductores es el hecho de que algunos de ellos han dedicado sonetos al amante de Laura. A través de este medio privilegiado, autores como Crespo ${ }^{34}$, Cabana ${ }^{35}$ o Desclot ${ }^{36}$ han conversado con Petrarca o han vertido en los moldes del aretino ideas o inquietudes de su cosecha propia.

Como consecuencia directa de este rasgo que acabamos de exponer surge la respuesta a la pregunta que formulamos al comienzo de este estudio y que aquí retomamos como colofón al mismo: ¿̇tiene el traductor la potestad de atribuirse la

31 En este sentido, se puede afirmar que aquella que Venuti identificó como la principal función del prefacio del traductor, esto es, la de «demystifying the illusion of transparency» (1995: 29), está más que probada en el corpus seleccionado.

32 Recuérdense los 20 sonetos (1980) de Cortines o las antologías de Desclot Saps la terra on floreix el llimoner (1999) o Cançoner. Tria de sonets (2003). cia en 1989

33 Piénsese en la primera traducción de Cabana de los Rvf, publicada por la Xunta de Gali-

${ }^{34}$ Gómez Bedate (1997: 16-17) publica el siguiente soneto de Crespo, en el que el traductor se dirige al aretino y lo emplaza a un encuentro tras su muerte: «Si te presté mi voz sin desviarme / y sin ahorrar mi lima, no es engańo / pensar que tras sufrir mi postrer daño / tú salgas a mi encuentro a saludarme. / Una veste, tal vez, vengas a darme / de otro color y de distinto paño / de la que visto ahora; y será extraño / que otra canción no quieras enseñarme. / Presumo que las rimas que tú hacías / y que los versos con que voy vistiendo / tus ideas, las de otros y las mías / sean silencio, si no ruido, / y que al canto que ya estoy presintiendo / me inicies tú, que ya lo has aprendido".

${ }_{35}$ Siguiendo los modelos de Rvf61, aunque sin dejar de lado los ecos dantescos (autor de cuya versión al gallego también se ocupará Cabana), el poeta compone un soneto a Amelia Outeiro Portela que transcribe en su introducción al Cancioneiro (2012: 29), se trata del siguiente: «Bendito sexa o ano, o mes, o día / que te encontrei no medio do camiño, / e andabas escollendo a flor do espiño / sen te mancar na espińa que fería; / bendita sexa a hora en que eu prendía / no teu claro mirar de trigo e liño, / e o instante en que probei o manselińo / mel da palabra túa ou amavía; / bendito sexa o intre e o segundo / en que determinei ser teu amigo / e camiñar contigo polo mundo; / bendito sexa o porto e a cidade / onde embarquei pra navegar contigo / nun navío de amor e de saudade».

$36 \mathrm{Al}$ proceso de traducir al aretino Desclot dedica el siguiente soneto, titulado «Pedra arca» y acompañado del paratexto explicativo «Traduint Petrarca», presente en su versión del Cançoner (2016: 41): «Et guio per camins sense atzavares, / pel bosc que només fressa ja el toixó, / al cim ventós de l'encinglat turó / on es fan cendra velles alimares; / t'ensenyo, pel camí, el parlar dels pares, / avidant, mot a mot, saule o tudó, / com si no fossis mestre i jo minyó / i el teu coratge ens hagués fet compares. / Perquè des de l'altura vegis néixer, / com rebrot en rabassa decadent, / com plançó tendre en socarrada feixa, / la paraula de sang arborescent / que per florir un minut al sol vol créixer, / arbre de marbre sobre el monument». 
propiedad del texto que está presentando o mediante el prólogo trata meramente de describir la intervención que ha llevado a cabo sobre un patrimonio que le es ajeno? Por la comunión espiritual más arriba descrita, estamos convencidos de que ninguno de nuestros traductores sentirá como ajena la obra de Petrarca y menos aún el texto del Cancionero. Asimismo, con respecto a cada una de las traducciones, la paternidad de Crespo, Cortines, Cabana y Desclot es indiscutible y de ello es una prueba irrefutable el modo en que, partiendo del material casi universal de los $R v f$, cada versión nos presenta una visión particular, la de cada uno de estos traductores y poetas.

En efecto y parafraseando a Desclot, si Petrarca, en tanto que el poeta más importante del siglo xiv, ya es de por sí un poeta de nuestros días, que el lector no especializado en la lírica trecentesca ni en sus epígonos lo perciba como tal es mérito único de aquellos traductores que, como los cuatro aquí estudiados, siguen contribuyendo con sus versiones a hacer realidad aquella máxima de Gorni según la cual «il futuro del petrarchismo è assicurato, e sarà radioso» (2006: 586). 


\section{BIBLIOGRAFÍA}

\section{Obras analizadas}

Petrarca, Francesco (1983): Cancionero, trad. de Ángel Crespo, Barcelona: Burguera.

Petrarca, Francesco (1989a): Cancionero, trad. de Jacobo Cortines, Madrid: Cátedra.

Petrarca, Francesco (2012): Cancioneiro, trad. de Darío Xohán Cabana, Lugo: Edicións da Curuxa.

Petrarca, Francesco (2016): Cançoner, trad. de Miquel Desclot, Barcelona: Proa.

\section{BiBLIOGRAFÍA CITADA}

AA.VV. (1989): Anthropos: Boletín de información y documentación. Número extraordinario 15, dedicado a Ángel Crespo.

AJa SÁnchez, José Luis (2015): "Ángel Crespo y el soneto xxxv. Un análisis traslativo del Canzoniere de Petrarca», Miscelánea Comillas, vol. 73, n. ${ }^{\circ}$ 142, 127-140.

Alain (1954): Propos sur l'éducation, París: Presses Universitaires de la France.

Arqués, Rossend (2005): «Tenues huellas del “Canzoniere” en catalán», Cuadernos de filología italiana 4 extra, 141-153.

Arqués, Rossend (2017): «L'art de fer-ho quasi igual. Desclot tradueix tot el Cançoner de Petrarca», Reduccions: revista de poesia 109, 153-160.

Barreiro Comedeiro, Moisés y Fátima Rodríguez Ruibal (2003): «O recurso ó léxico medieval no galego moderno", en María Álvarez de la Granja y Ernesto X. González Seoane (eds.), A estandarización do léxico, Santiago de Compostela: Instituto da lingua galega, 349-385.

Cammarota, Maria Grazia (2018): Tradurre: un viaggio nel tempo, Venecia: Edizioni Ca’ Foscari.

Carrera Díaz, Manuel (2005): «Una traducción contemporánea del “Canzoniere”», Cuadernos de filología italiana 4 extra, 133-139.

Chieregato, Chiara (2012): Ángel Crespo y la cultura italiana, tesis doctoral, Barcelona: Tesis doctorales de la Universitat Pompeu Fabra.

Desclot, Miquel (2017): «Anostrar Petrarca», Visat, revista digital de literatura i traducció del PEN catalá 23. URL: http://www.visat.cat/espai-traductors/esp/comentaris/62/212/-/miqueldesclot.html; 12/03/2021.

Eco, Umberto (2003): Dire quasi la stessa cosa, Milán: Bompiani.

Espadaler, Anton (2015): «Petrarca nella lirica catalana medievale», Quaderns d'italià 20, 89-109.

Gavagnin, Gabriella (2010): L'art de traduir Petrarca: les versions en català del Cançoner, Palma de Mallorca: Lleonard Muntaner.

Genette, Gérard (1987): Seuils, París: Seuil.

Gómez Bedate, Pilar (1997): «Ángel Crespo, poeta y traductor: el ideal de una vocación», en Soledad González Ródenas y Francisco Lafarga (eds.), Traducció i Literatura. Homenatge a Ángel Crespo, Vic: Eumo Editorial, 13-23. 
Gorni, Guglielmo (2006): «Perché non possiamo non dirci petrarchisti. Abbozzo di un bilancio di vita e opere», en Loredana Chines (ed.), Il petrarchismo. Un modello di poesia per l'Europa, 2 vols., Roma: Bulzoni, vol. II, pp. 581-589.

House, Juliane (2002): «Möglichkeiten der Übersetzungskritik», en Joanna Best y Sylvia Kalina (eds.), Übersetzen und Dommetschen. Eine Orientierungshilfe, Tubinga: Francke, 101-109.

Lejeune, Philippe (1975): Le Pacte autobiographique, París: Seuil.

Letawe, Céline (2018): «Quand le traducteur-préfacier parle de traduction. Fonctions d'un discours entre préface allographe et préface auctoriale», Palimpseste 31. URL: http://journals.openedition.org/palimpsestes/2583; 01/02/2021.

Luneau, Marie-Pier y Denis Saint-Amand (eds.) (2016): La Préface. Formes et enjeux d'un discours d'escorte, París: Classiques Garnier.

Mondola, Roberto (2017): «Recrear la lengua de Petrarca en el siglo xx: los Cancioneros de Ángel Crespo y Jacobo Cortines», Rivista di filologia e letterature ispaniche 20, 9-44.

Mounin, Georges (1994): Les Belles infidèles, Lille: Presses Universitaires de Lille.

Nida, Eugene A. y Charles R. TABeR (2003): The Theory and Practice of Translation, Leiden: Brill.

Petrarca, Francesco (1951): Rime, Trionfi e poesie latine, ed. de Ferdinando Neri, Guido Martelotti, Enrico Bianchi y Natalino Sapegno, Milán: Riccardi.

Petrarca, Francesco (1964): Canzoniere, ed. de Gianfranco Contini, notas de Daniele Ponchiroli, Turín: Einaudi.

Petrarca, Francesco (1967): Cancionero. Rimas en vida y en muerte de Laura, introducción y notas de Antonio Prieto, traducción de Enrique Garcés, Madrid: Magisterio Español.

Petrarca, Francesco (1976): El cancionero, trad. de Atilio Pentimalli, Sant Cugat del Vallés: Ediciones 29.

Petrarca, Francesco (1989b): Cancioneiro, trad. de Darío Xohán Cabana, Santiago de Compostela: Servicio de publicacións da Xunta de Galicia.

Petrarca, Francesco (1991): Canzoniere, ed. de Alberto Chiari, Milán: Mondadori.

Petrarca, Francesco (1996a): Canzoniere, ed. de Ugo Dotti, Roma: Donzelli.

Petrarca, Francesco (1996b): Canzoniere, ed. de Marco Santagata, Milán: Mondadori.

Proyecto Boscán. Catálogo de las traducciones españolas de obras italianas (hasta 1939). URL: http:// www.ub.edu/boscan; 15/02/2021.

Rico, Francisco (1983): «El destierro del verso agudo (con una nota sobre rimas y razones en la poesía del Renacimiento)", en AA. VV., Homenaje a José Manuel Blecua ofrecido por sus discípulos, colegas y amigos, Madrid: Gredos, 525-552.

Rodrigo Mora, María José (1996): «Laura traducida al español contemporáneo», en Associazione Ispanisti Italiani (eds.), Lo spagnolo di oggi: forme della comunicazione. Atti del Convegno di Roma dell'Associazione Ispanisti Italiani (15-16 marzo 1995), Roma: Bulzoni, 141-153.

Rodríguez Barcia, Moisés y Penélope Pedreira Rodríguez (2005): "Cuestiones y criterios en la traducción gallega del "Canzoniere". Su papel en la conformación del canon poético en Galicia”, Cuadernos de filología italiana 4 extra, 155-167.

Romera PAstor, Irene (2005): «Petrarca en la actualidad: ediciones y traducciones (siglos xix y xx)», en Mercedes Arriaga Flórez (ed.), Italia-Europa: literaturas comparadas, tradiciones y traducciones, Sevilla: Arcibel, 626-633. 
SEgre, Cesare (1983): «I sonetti dell'aura», Lectura Petrarce III, 57-78.

Shuttleworth, Mark y Moira Cowie (1997): Dictionary of Translation Studies, Londres: Routledge.

STÖRIG, Hans Joachim (1973): Das Problem des Übersetzens, Stuttgart: Wissenschaftliche Buchgesellschaft.

Venuti, Lawrence (1995): The Translator's Invisibility. A History of Translation, Londres-Nueva York: Routledge. 
